\title{
Venous Obstruction in Asymptomatic Patients Undergoing First Implantation or Revision of a Cardiac Pacemaker or Implantable Cardioverter-Defibrillator: A Retrospective Single Center Analysis
}

\author{
Venöse Obstruktionen bei asymptomatischen Patienten vor Erstimplantation \\ oder Revision eines Herzschrittmachers oder implantierbaren Cardioverter- \\ Defibrillators: Eine retrospektive Single-Center-Auswertung
}

Authors

Affiliations
C. C. Pieper ${ }^{1}$, V. Weis ${ }^{1}$, R. Fimmers ${ }^{2}$, I. Rajab ${ }^{3}$, M. Linhart ${ }^{4}$, H. H. Schild ${ }^{1}$, C. P. Nähle ${ }^{1}$

Department of Radiology, University of Bonn, Germany

Institute for Medical Biometry, Informatics and Epidemiology, University of Bonn, Germany

Department of Cardiac Surgery, University of Bonn, Germany

Department of Medicine-Cardiology, University of Bonn, Bonn, Germany

Key words
veins
angiography
obstruction/occlusion
implantable cardioverter-
defibrillator
pacemaker
venography

received 19.1.2015

accepted 7.6.2015

\section{Bibliography}

Dol http://dx.doi.org/ 10.1055/s-0035-1553351

Published online: 22.7.2015

Fortschr Röntgenstr 2015; 187: 1029-1035 @ Georg Thieme

Verlag KG Stuttgart - New York . ISSN 1438-9029

\section{Correspondence}

Dr. med. Claus Christian Pieper Radiologische Klinik,

Universitätsklinik Bonn

Sigmund-Freud-Str. 25

53105 Bonn

Germany

Tel.: ++ 49/02 28/28715237

Fax: ++49/02 28/28719083

claus.christian.pieper@ukb.unibonn.de

\section{Zusammenfassung}

\section{$\nabla$}

Ziel: Untersuchung der Inzidenz und möglicher Risikofaktoren von Obstruktionen der tiefen oberen Extremitätenvenen bei Patienten vor Erstimplantation und Revision von aktiven Herzimplantaten. Material und Methoden: Daten von asymptomatischen Patienten, die sich zwischen 09/2009 und 04/2012 einer Erstimplantation oder Revision eines aktiven Herzimplantates unterzogen haben, wurden ausgewertet. Das Vorliegen venöser Obstruktionen wurde mittels Venografie untersucht. Zusammenhänge zwischen Inzidenz einer venösen Obstruktion und patientenbezogenen sowie geräteabhängigen Faktoren wurden mittels exaktem Fischer-Test und univariater logistischer Regression untersucht. Eine multivariate logistische Regression wurde verwendet, um unabhängige Prädiktoren einer venösen Obstruktion zu bestimmen.

Ergebnisse: 456 Patienten erfüllten die Einschlusskriterien (330 Männer, 126 Frauen, 67,8 $\pm 12,9$ Jahre). Bei 100 Patienten wurde eine Erstimplantation, bei 356 eine Revision durchgeführt (mittlere Zeit seit der Implantation 82,5 \pm 75,3 Monate). Venöse Obstruktionen wurden bei $11,0 \%$ vor Erstimplantation bzw. 30,1\% vor Revision beobachtet. Ein Ventrikelersatzrhythmus war als einziger Faktor signifikant mit dem Auftreten einer Okklusion vor Erstimplantation assoziiert ( $\mathrm{p}<0,001)$. Vor Revisionen konnten männliches Geschlecht $(p=0.01)$, Zeit seit Implantation ( $p<0,0001)$, Ersatzrhythmus $(p=0,02)$, beeinträchtigte Gerinnungssituation $(p=0,02)$, Phenprocoumontherapie $(p=0,005)$ und peripher arterielle Verschlusskrankheit $(p=0,01)$ als unabhängige Prädiktoren identifiziert werden. Schlussfolgerung: Obwohl mehrere Risikofaktoren identifiziert werden konnten, ist eine verlässliche Vorhersage einer venösen Obstruktion nicht möglich. Wir empfehlen die Durchführung einer Venografie zur Vermeidung von Komplikationen bei allen Patienten vor Revision oder Aufrüstung

\section{Abstract \\ $\nabla$}

Purpose: To investigate the incidence and possible risk factors of upper deep vein obstruction in patients both prior to first cardiac device implantation and before device revision.

Materials and Methods: Records of asymptomatic patients undergoing contrast venography prior to implantation or revision of a cardiac device from $09 / 2009$ to $04 / 2012$ were reviewed. Venograms were used to determine the presence of venous obstruction. Interrelations between the incidence of venous obstruction and patient- or devicerelated parameters were identified using Fisher's exact test and univariate logistic regression. Multivariate logistic regression was used to identify independent predictors of venous obstruction. Results: 456 patients met the inclusion criteria (330 males, 126 females, $67.8 \pm 12.9$ years). 100 patients underwent first implantation, and 356 patients underwent device revision (mean time since implantation $82.5 \pm 75.3$ months). Venous obstruction was present in $11.0 \%$ and $30.1 \%$ before implantation and revision, respectively. Only presence of ventricular escape rhythm was significantly related to venous occlusion $(p<0.001)$ prior to first implantation. Prior to revision, significant predictors were male sex $(\mathrm{p}=0.01)$, time since implantation $(p<0.0001)$, presence of escape rhythm $(\mathrm{p}=0.02)$, compromised coagulation $(p=0.02)$, phenprocoumon $(p=0.005)$, and peripheral arterial disease $(p=0.01)$.

Conclusion: Although several risk factors could be identified, reliable prediction of venous obstruction was not possible. Therefore, we advocate performing venography in all patients prior to device revision or upgrade to avoid complications. In cases of first device implantation, the risks associated with venography should be weighed against the surprisingly high rate of deep upper vein obstruction. 
eines Implantates. Vor Erstimplantationen müssen die Risiken einer Venografie gegen die überraschend hohe Rate an tiefen Armvenenobstruktionen abgewogen werden.

Key Points:

- Die Prävalenz einer Obstruktion der tiefen oberen Extremitätenvenen ist erstaunlich hoch.

- Eine verlässliche Vorhersage einer venösen Obstruktion ist nicht möglich.

- Eine Kontrastvenografie sollte vor jeder Implantatrevision und jeder Aufrüstung durchgeführt werden.

- Vor Erstimplantation sollten prozedurale Risiken gegen die hohen Obstruktionsraten abgewogen werden.
Key points:

- Prevalence of upper extremity deep vein obstruction is surprisingly high.

- Reliable prediction of venous obstruction is not possible.

- Contrast venography should be performed prior to device revision/upgrade.

- Before first implantation procedure-related risks must be weighed against high obstruction rates.

Citation Format:

- Pieper CC, Weis V, Fimmers R etal. Venous Obstruction in Asymptomatic Patients Undergoing First Implantation or Revision of a Cardiac Pacemaker or Implantable Cardioverter-Defibrillator: A Retrospective Single Center Analysis. Fortschr Röntgenstr 2015; 187: 1029-1035

\section{Introduction}

$\nabla$

Upper extremity venous obstruction or thrombosis is generally considered to be a rare condition ( $1-4 \%$ of all deep vein thromboses) [1]. In patients with implantable transvenous cardiac devices, however, these conditions are common, with an incidence of venous obstruction of up to $50 \%$ of cases. Although clinically serious thromboembolic events only occur in $0.6 \%$ to $3.5 \%$ of cases, contrast venography has identified device-associated thrombosis in $35-45 \%$ of cases within the first year alone [2].

Pathogenesis of venous obstruction associated with cardiac device implantation is thought to be related to endothelial damage and disruption of laminar blood flow, leading to thrombus formation and organization with subsequent excessive fibrin deposition ultimately resulting in venous stenosis or occlusion [3]. These alterations usually develop within the first 3 months with diminishing incidence within 6 months after implantation [2]. Several risk factors for the development of venous obstruction both before $[1,4,5]$ and after [6 -9] cardiac device implantation have been described. However, most of the previous reports have only included relatively small patient populations $(<100-150$ patients). Furthermore, several studies were unable to determine any statistically significant risk factors whatsoever $[3,10]$. As venous obstruction can seriously complicate implantation or revision of a device, it should be excluded prior to surgery (first implant or revision/repeat surgery) [3]. Contrast venography as the gold standard [11], however, is an invasive procedure associated with contrast medium and radiation exposure. The identification of risk factors could therefore help to identify patients who should undergo evaluation before implantation.

The aim of the present study was therefore to retrospectively investigate the incidence and possible risk factors of upper deep vein obstruction in a larger patient population both prior to first cardiac device implantation and before device revision or upgrade.

\section{Materials and Methods}

$\nabla$

\section{Patient group and data collection}

Patients who underwent contrast venography prior to implantation or revision of a cardiac pacemaker or implantable cardioverter-defibrillator (ICD) from September 2009 through April 2012 were retrospectively reviewed for study eligibility. Informed consent for contrast venography was obtained from all patients at the time of examination. The study was approved by the local institutional review board. Patients were included in the study if no symptoms of upper extremity deep vein obstruction were reported. Patients were excluded from the analysis if imaging was not accessible electronically or only incomplete clinical data were available for review. Medical history, especially underlying heart disease and comorbidities (coronary artery disease; valvular heart disease; thrombophilia; compromised coagulation; cardiac arrhythmia; structural or congenital heart disease; renal disease; pulmonary disease; large vessel disease; cerebrovascular disease; peripheral vascular disease; malignancy), as well as other clinical and device-associated parameters (age, sex, body mass index (BMI), anticoagulation, previously placed central lines, type of pacemaker/ICD, type and number of leads/coils, as well as time since implantation) were recorded from archived patient data.

\section{Venography}

Patients with moderately elevated serum creatinine (1.5$2.0 \mathrm{mg} / \mathrm{dl}$ ) were prophylactically hydrated; patients with serum creatinine $>2.0 \mathrm{mg} / \mathrm{dl}$ were excluded. Bilateral contrast venography was performed via an 18 - $16 \mathrm{G}$ cannula placed in a peripheral vein on both forearms. A total of $30-50 \mathrm{ml}$ of contrast medium (Solutrast 300, Bracco Imaging) diluted 1:1 with saline was injected on both sides simultaneously. The contrast flow in the cephalic, axillary, subclavian and brachiocephalic vein, the superior vena cava as well as any collaterals, e.g. to the internal jugular vein, was documented using digital subtraction angiography with 2 frames per second.

Venograms were reviewed by two experienced radiologists independently to determine the presence of venous obstruction (venous stenosis $>70 \%$ (usually considered moderate to severe stenosis) and total occlusions, especially with the formation of venous collaterals).

\section{Data analysis}

Data are reported as means and standard deviations for continuous variables, and frequencies (in percentages) for categorical variables. Statistical analysis was performed separately for the groups of patients undergoing first implantation or revision of a cardiac device (SPSS v.22, IBM Corporation, NY, USA).

Univariate analysis was done using an exact Fisher's test for discrete variables and a univariate logistic regression model for continuous variables to find interrelations between the incidence of upper extremity venous obstruction and any of the patient-related parameters (sex, age, BMI, comorbidities, prior central line, nicotine abuse, prior CPR, prior thrombosis, arrhythmia, anticoagulation) or device-related parameters (device type, side of implantation, number of coils or leads, revisions/upgrades, time since implantation). 
Parameters were then entered into a multivariate logistic regression model to find independent predictors of venous obstruction prior to first implantation or revision of a cardiac device. In order to assess the performance of identified predictors, a receiver operating characteristic (ROC) curve was plotted.

\section{Results}

\section{$\nabla$}

\section{Patient characteristics}

From September 2009 through April 2012, a total of 658 patients underwent contrast venography at our institution of which 456 patients met the inclusion criteria (330 males, 126 females, 67.8 \pm 12.9 years (range: 25 - 95 years)). Within the group there was no case with clinically apparent signs of inflow obstruction such as facial or extremity swelling.

100 patients underwent venography prior to first implantation of a pacemaker $(n=51)$ or an ICD $(n=49)$. In 356 cases venography was performed prior to upgrade or revision of a pacemaker $(n=187)$ or an ICD $(n=169)$. The overall mean time since implantation of the devices was $82.5 \pm 75.3$ months (range $0-414$ months). 270 and 167 patients were under continuous antiplatelet (acetylsalicylic acid or clopidogrel) and anticoagulation (phenprocoumon) therapy, respectively. Detailed patient characteristics are given in $\bullet$ Table 1.

Table 1 Patient characteristics.

Tab. 1 Patientencharakteristika.

\begin{tabular}{|c|c|}
\hline patient number & $n=456$ \\
\hline mean age & $\begin{array}{l}67.8 \pm 12.9 \text { years } \\
\text { (range: } 25-95 \text { years) }\end{array}$ \\
\hline females/males & $126(27.6 \%) / 330(72.4 \%)$ \\
\hline BMI & $26.9 \pm 4.6$ \\
\hline \multicolumn{2}{|l|}{ associated diseases } \\
\hline - coronary artery disease & $213(46.7 \%)$ \\
\hline - valvular heart disease & $140(30.7 \%)$ \\
\hline - thrombophilia & $3(0.7 \%)$ \\
\hline - compromised coagulation & $5(1.1 \%)$ \\
\hline - cardiac arrhythmia & $314(68.9 \%)$ \\
\hline $\begin{array}{l}\text { - structural or congenital } \\
\text { heart disease }\end{array}$ & $39(8.6 \%)$ \\
\hline - renal disease & $70(15.4 \%)$ \\
\hline - pulmonary disease & $67(14.7 \%)$ \\
\hline - large vessel disease & $27(5.9 \%)$ \\
\hline - cerebral vascular disease & $76(16.7 \%)$ \\
\hline - peripheral arterial disease & $35(7.7 \%)$ \\
\hline - malignancy & $81(17.8 \%)$ \\
\hline previous thrombosis & $76(16.7 \%)$ \\
\hline prior central line & $138(30.3 \%)$ \\
\hline smoking & $107(23.5 \%)$ \\
\hline diabetes mellitus & $104(22.8 \%)$ \\
\hline arterial hypertension & $207(45.4 \%)$ \\
\hline \multicolumn{2}{|l|}{ anticoagulation } \\
\hline - antiplatelet therapy & $270(59.2 \%)$ \\
\hline - phenprocoumon & $167(36.6 \%)$ \\
\hline \multicolumn{2}{|l|}{ device } \\
\hline - pacemaker/ICD/CRT & $104 / 169 / 83$ \\
\hline - site of implantation & 296 left / 60 right \\
\hline - number of coils/leads & $201 \# 1-2 ; 155>2$ \\
\hline upgrades/revisions & $356(78.1 \%)$ \\
\hline time since implantation & $\begin{array}{l}82.5 \pm 75.3 \text { months } \\
\text { (range } 0-414 \text { months) }\end{array}$ \\
\hline
\end{tabular}

\section{Venographic findings}

In 338 patients ( $74.1 \%$ ), venograms showed normal contrast medium flow without any obstruction (89 prior to first implantation (89\%), 249 prior to device upgrade/revision (69.9\%)) (๑ Fig. 1). Venous obstruction was present in 11 (11\%) and 107 (30.1\%) cases before first implantation and revision, respectively ( $\bullet$ Fig. 2 ). The

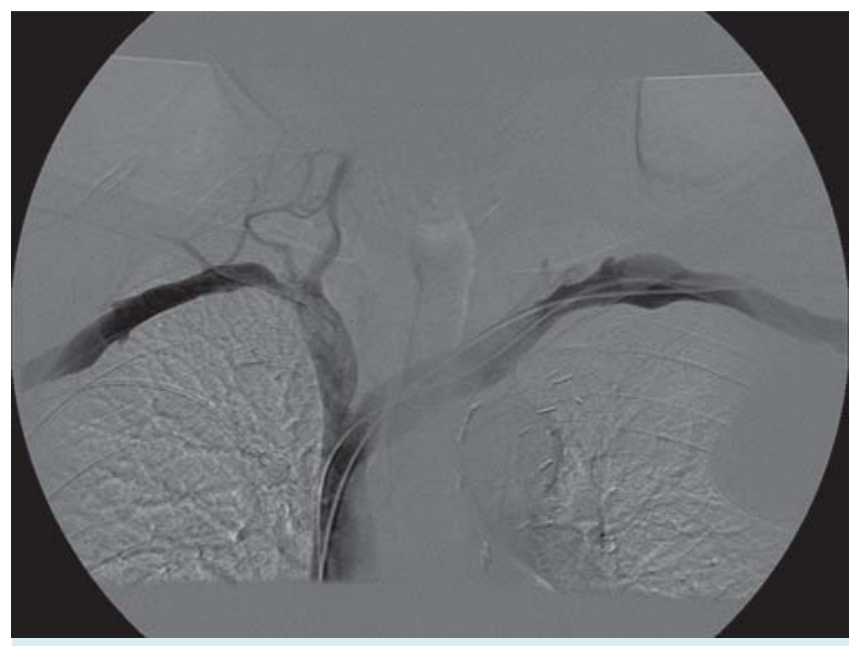

Fig. 1 Digital subtraction phlebography of a 67-year-old patient prior to revision of a left pectoral dual chamber pacemaker. The venogram shows normal contrast medium flow in the subclavian and brachiocephalic vein with inflow of unopacified blood from the internal jugular vein, as well as normal opacification of the superior vena cava.

Abb. 1 Digitale Subtraktionsphlebografie eines 67-jährigen Patienten vor Revision einer links pektoral einliegenden Zweikammerschrittmachers. Das Venogramm zeigt einen normalen Kontrastmittelfluss in den Vv. subclaviae und brachiocephalicae mit einem Einflussphänomen durch nicht kontrastiertes Blut der Venae jugulares internae, sowie eine normale Kontrastierung der V. cava superior.

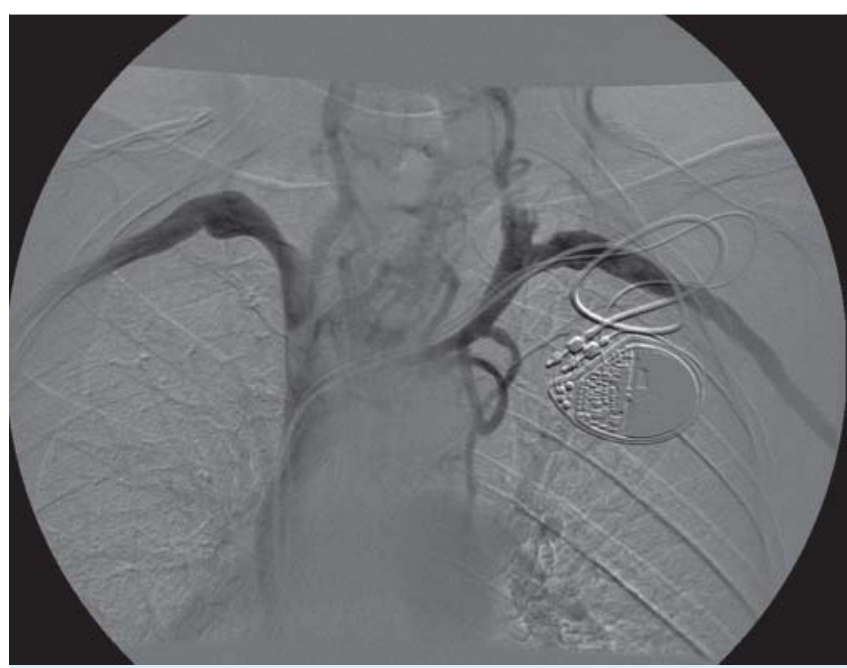

Fig. 2 Digital subtraction phlebography of a 77-year-old patient prior to revision of a left pectoral pacer. The venogram shows subtotal obstruction of the left brachiocephalic vein with filling of the mediastinal and paravertebral collaterals.

Abb.2 Digitale Subtraktionsphlebografie eines 67 jährigen-Patienten vor Revision eines links pektoral einliegenden Schrittmachers. Das Venogramm zeigt eine subtotale Obstruktion der linken V. brachiocephalica mit Kontrastierung von mediastinalen und paravertebralen Kollateralen. 
Table 2 Distribution of side of obstruction by side of device implantation in patients undergoing device revision or upgrade

Tab. 2 Verteilung der Obstruktionsseite nach Device-Implantationsort bei Patienten mit Devicerevision oder -upgrade.

\begin{tabular}{|lcc|}
\hline side of implantation & left $(\mathbf{n}=\mathbf{8 4} ; \mathbf{7 8 . 5} \%)$ & right $(\mathbf{n}=\mathbf{2 3} ; \mathbf{2 1 . 5} \%)$ \\
\hline obstruction & & \\
\hline - left & $65(77.4 \%)$ & $12(52.2 \%)$ \\
\hline - right & $10(11.9 \%)$ & $9(39.1 \%)$ \\
\hline - bilateral & $9(10.7 \%)$ & $2(8.7 \%)$ \\
\hline
\end{tabular}

majority of obstructions in both groups were observed in the subclavian vein (54.7\%). $75.3 \%$ of the obstructions in patients undergoing venography prior to revision occurred in the left subclavian vein. This preference for the left side was also observed for the brachiocephalic vein, while there was no clear side preference in patients undergoing first device implantation. In patients undergoing device revision or upgrade, overall $77.4 \%$ of obstructions were observed on the left side after left-sided device implantation while only $11.9 \%$ of obstructions occurred on the right side. In contrast we did not observe a preference of right-sided obstructions after device implantation on the right ( $\bullet$ Table 2 ).

Obstructions of the internal jugular vein or the superior vena cava were only observed in patients undergoing device revision. Congenital venous anomalies were a rare finding with only one patient presenting with a persistent left superior vena cava (0.2\%). Detailed venographic findings are given in 0 Table 3.

\section{Risk factors and predictors for venous obstruction}

In the group of patients undergoing venography prior to first implantation of a cardiac device, univariate analysis showed the presence of a ventricular escape rhythm to be the only variable to be significantly related to venous occlusion $(p<0.001)$. There was no significant difference between patients with and those without venous obstruction concerning all other analyzed variables. Ventricular escape rhythm also remained significant in logistic regression analysis $(\mathrm{p}<0.01)$.

Univariate analysis of venographic findings in patients prior to cardiac device upgrade/revision showed a higher incidence of previous venous thrombosis regardless of the anatomic region in the group with venous obstruction $(p=0.0313)$. Furthermore, the time since implantation was significantly associated with venous obstruction $(\mathrm{p}<0.0001)$. Compromised coagulation (e.g. due to thrombopenia) as well as the continued application of phenprocoumon were both also associated with venous obstruction ( $\mathrm{p}=0.0076$ and $\mathrm{p}=0.0283$, respectively). All univariate analysis results are summarized in $\bullet$ Table 4.

Multivariate analysis yielded the following significant predictors of venous obstruction: male sex $(p=0.0109$; OR 2.169), time since implantation ( $\mathrm{p}<0.0001$; OR 1.000), presence of a pacer or ventricular escape rhythm ( $p=0.0158$; OR 3.096), compromised coagulation $(\mathrm{p}=0.0238 ; 13.404)$, application of phenprocoumon $(\mathrm{p}=0.0045$; OR 2.085) as well as peripheral arterial disease $(p=0.0102$; OR 2.787). The ROC curve of the significant parameters is given in $\bullet$ Fig. 3 with an area under the curve (AUC) of 0.724 indicating fair accuracy in predicting venous obstruction.
Table 3 Venographic findings. ${ }^{1}$

Tab. 3 Venografie-Befunde.

\begin{tabular}{|c|c|c|c|}
\hline & $\begin{array}{l}\text { patients prior } \\
\text { to first im- } \\
\text { plantation } \\
(n=100)\end{array}$ & $\begin{array}{l}\text { patients un- } \\
\text { dergoing up- } \\
\text { grade/revision } \\
(n=356)\end{array}$ & $\begin{array}{l}\text { total } \\
(n=456)\end{array}$ \\
\hline $\begin{array}{l}\text { patients with- } \\
\text { out obstruction }\end{array}$ & $89(89.0 \%)$ & $249(69.9 \%)$ & $338(74.1 \%)$ \\
\hline $\begin{array}{l}\text { patients with } \\
\text { obstruction }\end{array}$ & $11(11.0 \%)$ & 107 (30.1\%) & $118(25.9 \%)$ \\
\hline - right & $3(27.3 \%)$ & $19(17.8 \%)$ & $22(18.6 \%)$ \\
\hline - left & $5(45.4 \%)$ & $77(72.0 \%)$ & 82 (69.5\%) \\
\hline - bilateral & $3(27.3 \%)$ & $11(10.2 \%)$ & $14(11.9 \%)$ \\
\hline $\begin{array}{l}\text { obstructed } \\
\text { veins }\end{array}$ & 14 & 142 & 156 \\
\hline axillary vein & 0 & $4(2.8 \%)$ & $4(2.6 \%)$ \\
\hline - right & 0 & 0 & 0 \\
\hline - left & 0 & 4 & 4 \\
\hline subclavian vein & $6(42.9 \%)$ & $81(57.0 \%)^{1}$ & $87(55.7 \%)$ \\
\hline - right & 5 & 22 & 27 \\
\hline - left & 1 & 59 & 60 \\
\hline $\begin{array}{l}\text { brachiocepha- } \\
\text { lic vein }\end{array}$ & $8(57.1 \%)$ & $52(36.6 \%)^{1}$ & $60(38.4 \%)$ \\
\hline - right & 3 & 11 & 14 \\
\hline - left & 5 & 41 & 46 \\
\hline $\begin{array}{l}\text { internal jugular } \\
\text { vein }\end{array}$ & 0 & $1(0.8 \%)$ & $1(0.7 \%)$ \\
\hline $\begin{array}{l}\text { superior vena } \\
\text { cava }\end{array}$ & 0 & $4(2.8 \%)$ & $4(2.6 \%)$ \\
\hline
\end{tabular}

${ }^{1}$ In patients undergoing device revision, seven had bilateral subclavian vein obstruction and two had bilateral brachiocephalic vein obstruction on venography. In der Patientengruppe vor Devicerevision lagen bei sieben Patienten eine bilaterale Obstruktion der V. subclavia und bei zwei Patienten eine bilaterale Obstruktion der V. brachiocephalica vor.

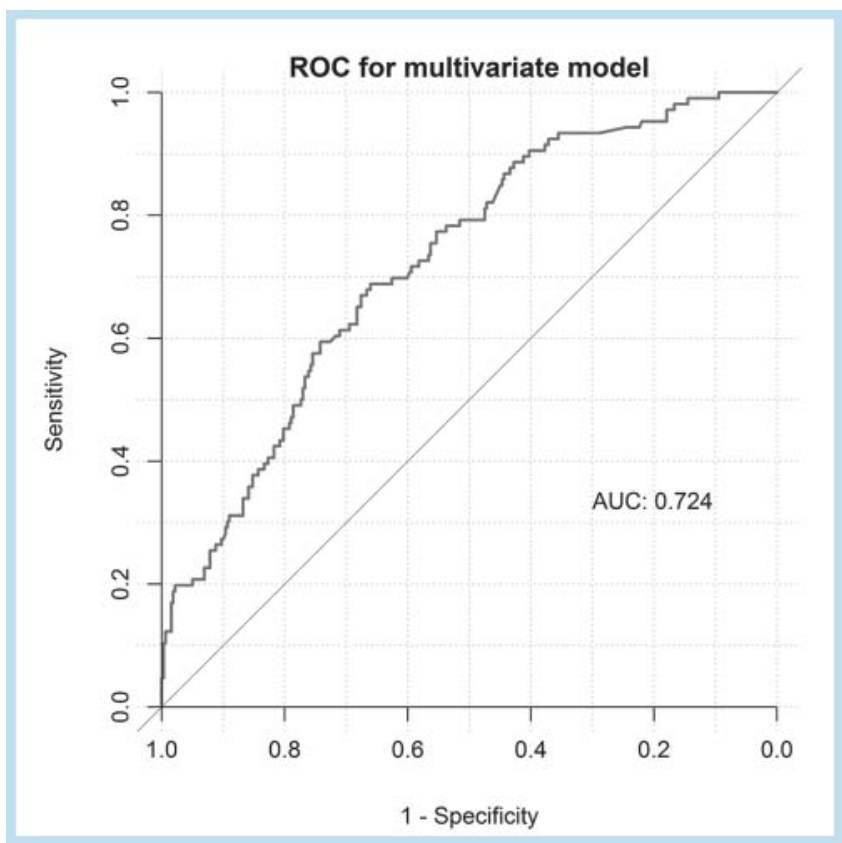

Fig. 3 ROC curve.

Abb. 3 ROC-Kurve 


\begin{tabular}{|c|c|c|c|c|c|}
\hline \multirow[b]{2}{*}{ parameter } & \multicolumn{2}{|c|}{ prior to first implantation } & \multicolumn{2}{|l|}{ upgrades/revisions } & \multirow{5}{*}{$\begin{array}{l}\text { Table } 4 \text { Influencing factors of } \\
\text { venous obstruction. Results of } \\
\text { univariate analysis (exact Fisher's } \\
\text { test and logistic regression). Sta- } \\
\text { tistically significant results written } \\
\text { in bold. }\end{array}$} \\
\hline & p-value (two-sided) & odds ratio & p-value (two-sided) & odds ratio & \\
\hline male sex & 0.0615 & 1.1691 & 0.0724 & 1.6770 & \\
\hline age & 0.9270 & 0.997 & 0.1561 & 0.988 & \\
\hline BMI & 0.7194 & 1.028 & 0.9122 & 0.997 & \\
\hline time since implantation (years) & & & $<0.0001$ & 1.0000 & Tab. 4 Einflussfaktoren einer ve- \\
\hline previous central venous line & 0.5364 & 1.5385 & 0.5843 & 0.8490 & nösen Obstruktion. Ergebnisse \\
\hline ASS/Clopidogrel & 0.2889 & 3.4848 & 0.2956 & 1.2862 & der univariaten Analyse (exakter \\
\hline phenprocoumon & 0.5025 & 0.5103 & 0.0238 & 1.7152 & Fischer-Test und logistische Re- \\
\hline device type (ICD/Pacer) & & & 0.3850 & NA & gression). Statistisch signifikante \\
\hline side of implantation (left) & & & 0.3399 & 1.3791 & Ergebnisse sind fett hervorgeho- \\
\hline no. of coils/leads $(\leq 2 ;>2)$ & & & 0.2144 & 1.3813 & ben. \\
\hline upgrade/revision & & & 0.2397 & 2.1157 & \\
\hline coronary artery disease & 0.3302 & 2.4052 & 0.1572 & 1.4230 & \\
\hline valvular heart disease & 0.5209 & 0.5521 & 0.6094 & 0.8655 & \\
\hline thrombophilia & 1.000 & 0.8889 & 0.0886 & NA & \\
\hline $\begin{array}{l}\text { compromised coagulation (not } \\
\text { including anticoagulation) }\end{array}$ & 1.000 & 0.8889 & 0.0076 & & \\
\hline cardiac arrhythmia & 1.000 & 0.8571 & 0.8978 & 0.9461 & \\
\hline $\begin{array}{l}\text { structural or congenital heart } \\
\text { disease }\end{array}$ & 0.5125 & 1.6800 & 0.8430 & 0.8698 & \\
\hline renal disease & 0.7026 & 1.3816 & 1.000 & 0.9623 & \\
\hline pulmonary disease & 1.000 & 0.5357 & 0.7432 & 0.8450 & \\
\hline large vessel disease & 1.000 & 0.8842 & 1.000 & 0.8738 & \\
\hline cerebral vascular disease & 1.000 & 1.1905 & 0.1236 & 1.5878 & \\
\hline peripheral arterial disease & 0.0779 & 4.3929 & 0.1169 & 1.9436 & \\
\hline smoking & 0.7294 & 1.3846 & 0.8882 & 0.9238 & \\
\hline diabetes mellitus & 1.000 & 0.8170 & 0.1146 & 0.5988 & \\
\hline arterial hypertension & 0.7539 & 0.7447 & 0.4141 & 1.2245 & \\
\hline previous CPR & 0.6500 & 1.4259 & 0.2836 & 1.3296 & \\
\hline ventricular escape rhythm & $<0.0001$ & NA & 0.0653 & NA & \\
\hline previous thrombosis & 0.2038 & 0.8690 & 0.0313 & 1.8871 & \\
\hline malignancy & 0.1614 & 2.5379 & 0.7499 & 1.0944 & \\
\hline
\end{tabular}

\section{Discussion}

The results of this study demonstrate that upper extremity venous obstruction following cardiac pacemaker or ICD implantation is frequently encountered (i. e., in approx. 1/3 of all cases), even in asymptomatic patients as in this study. In cases of planned first device implantation, obstructions can be observed in $11.0 \%$ of cases. These results are in line with previously published reports $[1,2,5]$.

Systematic data on venous obstruction prior to cardiac device implantation are scarce. Numerous different possible risk factors for the development of venous obstruction after cardiac device placement have been reported, but the exact etiological factors of thrombosis and subsequent possible chronic venous obstruction following device implantation with transvenous leads/coils are still under debate. After pacemaker implantation those risk factors are impaired left ventricular function, atrial fibrillation, systemic infection, no anticoagulation therapy, history of thrombosis, multiple leads, biventricular device, previously placed temporary pacing leads and additional ICD shock coil $[6-8,12,13]$. Likewise possible risk factors after ICD implantation are previously placed pacemaker leads, dual shocking coil leads and number of leads $[8,14]$.

As the placement of new leads or revision/extraction of electrodes may be difficult or impossible in cases of venous obstruction, the question as to which patients should undergo invasive contrast venography remains unanswered [15]. Some authors recommend venography only in cases with clinically detectable signs of obstruction [16]. However, the development of often clinically inapparent collaterals may disguise even complete occlusion of the upper extremity veins [17]. Therefore, others authors advocate performing contrast venography in patients at risk of developing venous obstruction, e.g. in patients with a history of previous pacemaker implantation. However, neither laboratory nor single clinical parameters seem to be able to predict the occurrence of venous obstruction. However, a combination of classic risk factors such as cancer, prior thromboembolism or a history of previous pacemaker implantation seems to be observed significantly more frequently. Other studies failed to find any risk factors whatsoever $[2,3,10]$.

Therefore, the aim of the present study was to investigate the incidence of upper extremity venous obstruction, and to identify risk factors in a large patient population.

Venographic studies investigating venous occlusion prior to device implantation in general found a prevalence of $4.4-13.7 \%$ $[5,10,18]$. The occurrence of upper extremity deep vein thrombosis prior to any cardiac device implantation is often associated with malignancy and/or central venous lines. In a study on patients with superior vena cava (SVC) and brachiocephalic vein thrombosis, $74 \%$ had cancer $[4,19]$. Furthermore, Linhart et al. identified a trend toward higher obstruction rates in patients with a history of prior pacemaker implantation [5]. While other studies have described malignancy and/or central venous lines as possible risk factors for venous occlusion, we could not corroborate these results in our study with both malignancy and central venous lines not being significantly related to venous occlu- 
sion $[4,19]$. Although clinically apparent pulmonary embolism is less frequent in upper- than in lower-extremity deep vein thrombosis, patient outcome after three months does not differ significantly between both groups, making upper-extremity deep vein thrombosis a relevant, clinically under-recognized entity [1]. Venous obstruction has been reported to be significantly more frequent on the left side prior to device implantation [18]. However, the reason for this finding remains unclear, and no clear preference of the left side could be demonstrated in our study population. In the subgroup of patients undergoing device upgrade or revision, however, obstructions were more frequent on the left side, supposedly due to most devices previously being implanted on the left pectoral. However, the influence of the device implantation side remains unclear. While after left-sided device implantation there is a clear preference of more than $3 / 4$ of obstructions occurring on the left side, only about $40 \%$ of patients showed right-sided obstruction after right pectoral device implantation. Surprisingly there was no clear influence of the implantation side in uni- or multivariate analyses which might be due to the rather small number of patients receiving right-sided device implantation. The only study published to date investigating the rate of venous obstruction both prior to as well as after implantation showed a significant increase in the occurrence of obstruction from $13.7 \%$ to $32.9 \%$ after implantation [10], which is comparable to our own results ( $11.0 \%$ prior to implantation and $30.1 \%$ prior to upgrade/revision). Overall venous obstruction (any grade of stenosis) was described in $25-50 \%$ of cases after ICD placement $[3,14]$ and in $14-64 \%$ after pacemaker implantation $[6,7,9,10,12]$, but to date no direct comparison of venous obstruction rates between pacemaker and ICD patients is available. In our analysis we found no statistically significant difference in the incidence of venous obstruction when comparing patients with an ICD or pacemaker $(\mathrm{p}=0.3850)$.

A persistent left SVC (PLSVC) was found in only one patient $(0.2 \%)$, although it was the most common thoracic venous abnormality. While the prevalence of PLSVC is substantially higher with 3$10 \%$ in patients with congenital heart disease, the prevalence in our asymptomatic patient population is in good agreement with the rates of $0.4-0.7 \%$ observed in previous studies $[5,18]$.

Our results show that venous obstruction was significantly associated with the time since lead implantation, pacer or ventricular escape rhythm as well as with male sex. Ventricular escape rhythm being associated with venous obstruction seems to be in line with a previous study where impaired left ventricular function was reported as being a risk factor [6]. Ventricular escape rhythm with no or asynchronous atrial function might therefore contribute to obstruction formation due to altered flow dynamics in the central venous system. Additionally, previous thrombosis was identified as a risk factor in univariate analysis in the present study. However, in contrast to previous studies [6-9, 12, 14], the number of implanted leads, device type (ICD, pacemaker), previous central line placement as well as history of malignancy were not significantly associated with venous obstruction. Especially the impact of multiple leads is of interest when considering possible lead extraction of superfluous leads [20]. In our cohort we did not find any association of increased risk of venous obstruction with multiple leads being implanted which is in line with other studies as well $[13,21]$.

In a prospective study by Costa et al., long-term anticoagulation with warfarin after device implantation in patients with a high risk of thrombosis led to a significantly lower frequency of venous thrombosis compared to the control group without warfar- in $(38.6 \%$ vs. $60.4 \%)$ [22]. In contrast to these, the results of the present study showed that venous obstruction was more frequent in patients being treated with phenprocoumon - typically used to achieve anticoagulation at our institution - as well as in patients with impaired coagulation (e.g. due to thrombopenia). It is unclear why these patients developed obstructions more often. It is important to note, however, that in contrast to the study by Da Costa et al. [6], anticoagulation was not routinely administered to the patients immediately after implantation, but was prescribed for other medical conditions such as atrial fibrillation. It is possible that the patient group receiving phenprocoumon had an intrinsically higher risk of developing thromboses or had already developed an obstruction at the time phenprocoumon therapy was started. Anticoagulation therapy should therefore not be withheld from patients and further research into this question seems to be warranted.

Interestingly, a different set of risk factors from that mentioned above has been reported in patients with clinically manifest thrombosis with extremity swelling or pain [23]. In a series of 20 patients with symptomatic upper-extremity deep vein thrombosis, reported risk factors included diabetes, smoking, hypertension, body mass index $>30 \mathrm{~kg} / \mathrm{m}^{2}$, history of myocardial infarction, chronic obstructive pulmonary disease, and congestive heart failure. However, in our analysis we could not corroborate the described risk factors in our asymptomatic patient population. Furthermore, antiplatelet therapy has been reported as ineffective for preventing device-associated thrombosis [23]. This is in good agreement with the results of the present study in which antiplatelet therapy was also shown not to be a significant preventive factor.

Duplex sonography as an alternative imaging tool is well suited to evaluate the peripheral veins (cephalic and subclavian vein) $[24,25]$. Although it has a somewhat limited diagnostic value for central veins, sonography should be considered as an alternative especially in younger patients, or in patients with contraindications for contrast media exposure such as previous allergic reaction, chronic kidney disease > grade II, and previous contrast-induced nephropathy. While magnetic resonance imaging often represents an alternative imaging modality in patients with known kidney disease and allows for imaging of the entire thoracic vasculature, its use is not recommended by current guidelines due to the presence of ferromagnetic material [26].

There are several limitations to the present study. We performed the study retrospectively with inherent problems associated with this approach. Venography in patients undergoing upgrade/revision was not available prior to first implantation. Therefore, the exact rate of obstruction prior to implantation in this group was not known, limiting the conclusiveness of the statistical analysis of the incidence of obstruction at the time of revision. Furthermore, no data on technical problems during device revision in those patients with obstruction was available, thus not allowing any conclusion about the implications of an obstruction. The presence of thrombophilia in the patient group was not systematically evaluated. It is therefore arguable that the number of patients suffering from thrombophilia may have been underestimated. Finally, comparison of our results to other studies as well as comparison of those studies to one another is limited due to varying methodology (e. g. different definitions of venous stenosis).

The prevalence of deep upper-extremity vein obstruction even in asymptomatic patients is higher than clinically expected ( $11 \%$ prior to device implantation, $30.1 \%$ prior to upgrade/revision). The presence of a ventricular escape rhythm was the only signif- 
icant risk factor for obstruction in patients undergoing their first device implantation. In cases of device revision/upgrade, venous obstruction was associated with male sex, pacer or ventricular escape rhythm and peripheral arterial disease as well as longer time since device implantation. As all available data fail to allow for reliable prediction of venous obstruction, we advocate performing contrast venography before any device revision/upgrade in order to avoid intra-procedural complications. Before undertaking contrast venography in cases of first device implantation, it is necessary to evaluate procedure-related risks, such as contrast-induced nephropathy, radiation exposure and allergic reaction as well as patient age. These should be weighed against the surprisingly high rate of deep upper vein thrombosis even in asymptomatic patients. The role of anticoagulation remains uncertain.

\section{Clinical Relevance of the Study}

- The prevalence of upper-extremity deep vein obstruction is as high as $11 \%$ prior to first device implantation and $30 \%$ prior to upgrade or revision, even in asymptomatic patients.

- Reliable prediction of obstruction remains difficult so that imaging assessment of vessel patency should be performed.

- The influence of anticoagulation on obstruction in this patient population remains unclear.

- Contrast venography should be performed prior to any device upgrade/revision.

- Before first device implantation, venography can be performed after thorough evaluation of procedure-related risks.

\section{References}

1 Muñoz FJ, Mismetti P, Poggio R. RIETE Investigators. et al. Clinical outcome of patients with upper-extremity deep vein thrombosis: results from the RIETE Registry. Chest 2008; 133: 143-148

2 Antonelli $D$, Turgeman $Y$, Kaveh $Z$ et al. Short-term thrombosis after transvenous permanent pacemaker insertion. Pacing Clin Electrophysiol 1989; 12: 280-282

3 Sticherling C, Chough SP, Baker RL et al. Prevalence of central venous occlusion in patients with chronic defibrillator leads. Am Heart J 2001; 141: $813-816$

4 Sakakibara Y, Shigeta O, Ishikawa S et al. Upper extremity vein thrombosis: etiologic categories, precipitating causes, and management. Angiology 1999; 50: 547-553

5 Linhart M, Schwab JO, Bellmann B et al. Prevalence of asymptomatic upper extremity venous obstruction in 302 patients undergoing first implantation of cardioverter defibrillator. Pacing Clin Electrophysiol 2011; 34: 684-689

6 Da Costa SS, Scalabrini NA, Costa R et al. Incidence and risk factors of upper extremity deep vein lesions after permanent transvenous pacemaker implant: a 6-month follow-up prospective study. Pacing Clin Electrophysiol 2002; 25: 1301 -1306

7 Korkeila P, Nyman K, Ylitalo A et al. Venous obstruction after pacemaker implantation. Pacing Clin Electrophysiol 2007; 30: 199-206
8 Haghjoo M, Nikoo MH, Fazelifar AF et al. Predictors of venous obstruction following pacemaker or implantable cardioverter-defibrillator implantation: a contrast venographic study on 100 patients admitted for generator change, lead revision, or device upgrade. Europace 2007; 9: $328-332$

9 Bulur S, Vural A, Yazıcı M et al. Incidence and predictors of subclavian vein obstruction following biventricular device implantation. J Interv Card Electrophysiol 2010; 29: 199-202

10 Oginosawa $Y$, Abe H, Nakashima $Y$. The incidence and risk factors for venous obstruction after implantation of transvenous pacing leads. Pacing Clin Electrophysiol 2002; 25: 1605-1611

11 Maas R, Nicolas $V$, Mügge-Hamann $U$ et al. Phlebography of the upper extremity. I. The technic and findings in 230 studies. Röfo 1995; 162: $33-38$

12 Bracke F, Meijer A, Van Gelder B. Venous occlusion of the access vein in patients referred for lead extraction: influence of patient and lead characteristics. Pacing Clin Electrophysiol 2003; 26 (8): 1649-1652

13 van Rooden CJ, Molhoek SG, Rosendaal FR et al. Incidence and risk factors of early venous thrombosis associated with permanent pacemaker leads. J Cardiovasc Electrophysiol 2004; 15: 1258 - 1262

14 Lickfett L, Bitzen A, Arepally A et al. Incidence of venous obstruction following insertion of an implantable cardioverter defibrillator. A study of systematic contrast venography on patients presenting for their first elective ICD generator replacement. Europace 2004; 6: 25 - 31

15 Winters SL, Curwin JH, Sussman JS et al. Utility and safety of axillo-subclavian venous imaging with carbon dioxide (CO) prior to chronic lead system revisions. Pacing Clin Electrophysiol 2010; 33: 790 - 794

16 Kar AK, Ghosh S, Majumdar A et al. Venous obstruction after permanent pacing. Indian Heart J 2000; 52: 431 - 433

17 Kommareddy A, Zaroukian MH, Hassouna HI. Upper extremity deep venous thrombosis. Semin Thromb Hemost 2002; 28: 89-99

18 Oginosawa $Y$, Abe $H$, Nakashima Y. Prevalence of venous anatomic variants and occlusion among patients undergoing implantation of transvenous leads. Pacing Clin Electrophysiol 2005; 28: 425-428

19 Otten TR, Stein PD, Patel KC et al. Thromboembolic disease involving the superior vena cava and brachiocephalic veins. Chest 2003; 123: $809-812$

20 Bracke FA. Yes we can! But should we? Lead extraction for superfluous pacemaker and implanted cardioverter-defibrillator leads. Europace 2009; 11: 546-547

21 de Cock CC, Vinkers M, Van Campe LC et al. Long-term outcome of patients with multiple $(>$ or $=3$ ) noninfected transvenous leads: a clinical and echocardiographic study. Pacing Clin Electrophysiol 2000; 23: $423-426$

22 Costa R, Da Silva KR, Rached $R$ et al. Prevention of venous thrombosis by warfarin after permanent transvenous leads implantation in high-risk patients. Pacing Clin Electrophysiol 2009; 32 (Suppl 1): 247-251

23 Mandal S, Pande A, Mandal D et al. Permanent pacemaker-related upper extremity deep vein thrombosis: a series of 20 cases. Pacing Clin Electrophysiol 2012; 35 (10): 1194-1198

24 Zuber M, Huber P, Fricker $U$ et al. Assessment of the subclavian vein in patients with transvenous pacemaker leads. Pacing Clin Electrophysiol 1998; 21: $2621-2630$

25 Chen JY, Chang KC, Lin YC et al. Pre-procedure duplex ultrasonography to assist cephalic vein isolation in pacemaker and defibrillator implantation. J Interv Card Electrophysiol 2005; 12: 75-81

26 Brignole M, Auricchio A, Baron-Esquivias G et al. European Society of Cardiology (ESC); European Heart Rhythm Association(EHRA). 2013 ESC guidelines on cardiac pacing and cardiac resynchronization therapy: the task force on cardiac pacing and resynchronization therapy of the European Society of Cardiology (ESC). Developed in collaboration with the European Heart Rhythm Association (EHRA). Europace 2013; 15 : $1070-1118$ 